\title{
A visão dos universitários sobre o papel do psicólogo: uma representação social
}

The vision of the undergraduate on the role of the psychologist: a social representation Una visión de la universidad sobre el papel del psicólogo: una representación social

\author{
Washingthon Napoleão Eufrázio* \\ Aline Gomes* \\ Marilise Katsurayama**
}

\begin{abstract}
Resumo
O objetivo desta pesquisa foi identificar as representações sociais nos discursos dos acadêmicos das áreas das Ciências Humanas, Exatas e da Saúde, a respeito do aluno de Psicologia e da atuação do psicólogo, tendo com base a teoria das representações sociais. Participaram desta pesquisa acadêmicos da Universidade Federal do Amazonas (UFAM), num total de 120 alunos, que responderam a um questionário aberto com três questões e um termo de consentimento livre e esclarecido, sendo que os resultados foram agrupados e analisados. Para a análise dos dados, foi utilizada a técnica da análise temática ou categorial, ou seja, baseandose em operações de desmembramento do texto em unidades. Foram identificados diversos preconceitos e estereótipos em relação ao aluno de Psicologia. A maioria dos universitários reconhece a importância do psicólogo para a sociedade, mas grande parte não consegue associá-lo à sua a área de atuação. A percepção dos universitários sobre as contribuições da Psicologia é muito insipiente em relação aos vários benefícios que ela pode trazer tanto para os acadêmicos quanto para as outras áreas do conhecimento.
\end{abstract}

Palavras-chave: Representaçōes sociais. Universitários. Psicólogos.

\footnotetext{
Abstract

The objective of this research was to identify the social representations in the discourse of academics areas of humanities, exact and health, concerning the student of psychology and the

Texto recebido em janeiro 2013 e aprovado para publicação em novembro de 2013.

Discente da Faculdade de Psicologia da Universidade Federal do Amazonas (UFAM). Endereço: Rua Cubatão, 1648 Redenção, Manaus-AM. CEP: 69047-020. E-mail: w.napoleao@yahoo.com.br.

** Discente da Faculdade de Psicologia da UFAM. Endereço: Rua 58, n 26, Quadra 118 - Bairro Cidade Nova, Conjunto Nova Cidade, Manaus-AM. CEP: 69097-378.E-mail: alinegomes85@gmail.com.

*** Mestra em Saúde, Sociedade e Endemias na Amazônia, graduada em Psicologia e Medicina pela UFAM. Endereço: Avenida General Rodrigo Octávio, 6200 - Coroado, Manaus-AM. CEP: 69077-000.E-mail: marilise-k@hotmail.com.
} 
psychologist, and based on the Theory of Social Representations. Participate in this research, academic, Federal University of Amazonas (UFAM), a total of 120 students answered an open questionnaire with three questions and a Statement of Informed Consent, and the results were recorded and analyzed. For data analysis we used the technique of thematic analysis or categorical, in other, based on operations dismemberment of text units. We identified many prejudices and stereotypes in relation to the student of psychology. Most university recognizes the importance of the psychologist for society, but most cannot associate it with their area of expertise. The perception of students about the contributions of psychology is very incipient forward to many benefits it can bring both to academics and to other areas of knowledge.

Keywords: Social representations. University. Psychologists.

\section{Resumen}

El objetivo de esta investigación fue identificar las representaciones sociales en el discurso de los académicos de las áreas de Ciencias Humanas, Exactas y Salud sobre el estudiante de psicología y la actuación del psicólogo, con base en la teoría de las representaciones sociales. Participaron en esta investigación académicos de la Universidad Federal de Amazonas (UFAM), en total 120 estudiantes que respondieron a un cuestionario abierto de 3 preguntas y un término de consentimiento, libre y aclarado. y los resultados fueron registrados y analizados. Para el análisis de los datos se utilizó la técnica del análisis temático o categorial, es decir, que se basa en operaciones de desmembración del texto en unidades. Se identificaron muchos prejuicios y estereotipos sobre los estudiantes de psicología. La mayoría de los universitarios reconoce la importancia para la sociedad de los psicólogos, pero la mayoría no los logra asociar con su área de especialización. La percepción de los estudiantes universitarios sobre los aportes de la Psicología es muy incipiente en relación con los diversos beneficios que puede aportar tanto a los académicos como a otras áreas del conocimiento.

Palabras clave: Representaciones sociales. Universitarios. Psicólogos. 


\section{Introdução}

A Psicologia social éo estudo das "manifestaçóes comportamentais suscitadas $\triangle$ pela interação de uma pessoa com pessoas, ou pela mera expectativa de tal situação" (Rodrigues, 1984), estuda as relações interpessoais, tais como percepção social, a comunicação, atitudes, o processo de socialização, os grupos e papéis sociais e os fatores psicológicos da vida social. Entre os estudos da Psicologia social, desenvolveu-se o conceito das representaçóes sociais, que, há quase 50 anos, vem se constituindo como campo influente de investigação e pesquisa, tornando-se uma interface entre os vários campos das Ciências Humanas e Sociais, como a Sociologia, Psicologia, Ciências Políticas, entre outros (Almeida, 2009).

Segundo Guareschi e Jovchelovitch (1994), o conceito de representação social nasceu na Sociologia e na Antropologia, nas obras de Durkheim e Bruhl. Esse conceito teve um importante papel análogo na teoria da linguagem de Saussure, na teoria de Piaget, ou ainda na do desenvolvimento cultural de Vigotsky. Um dos principais nomes do estudo da teoria das representaçóes sociais foi o francês Serge Moscovici, preocupando-se não apenas em investigar como o conhecimento é produzido, mas qual seria a influência desse conhecimento nas práticas sociais (Oliveira, 2004).

A Psicologia social trabalha as representações sociais no âmbito do seu objeto de análise (a relação indivíduo-sociedade) e de um interesse pela cognição, pensa sobre como os indivíduos, os grupos, os sujeitos sociais desenvolvem seu conhecimento a partir da sua inscrição social, cultural por um lado e, por outro, como a sociedade se dá a conhecer e constrói esse conhecimento com os indivíduos. Estuda a interação entre indivíduos e sociedade para construir a realidade por meio da comunicação. Umas das funções das representações sociais, portanto, é facilitar a comunicação entre indivíduos e possibilitar que conhecimentos estranhos se tornem familiares (Moscovici, 2003).

Representações sociais são tipos de conhecimentos práticos utilizados para percepção do mundo social, ideológico e material. São socialmente elaboradas e compartilhadas, facilitam a elaboração de uma realidade habitual e possibilitam a comunicação entre os indivíduos (Porto, 2009). Além disso, tem papel relevante na formação de conduta, pois é ela quem modela o comportamento e justifica sua expressão.

Outro aspecto importante é o estereótipo que é criado pelos acadêmicos. Do ponto de vista da organização do real, o estereótipo social é uma forma de categorização da realidade que tem uma forte coloração avaliativa e afetiva, geralmente negativa, mas que também pode surgir com conteúdo positivo. 
Sejam negativos ou positivos, os estereótipos têm como função reduzir a incerteza e organizar a realidade presente, tornando-se, eles mesmos, elementos "reais" formadores desse mesmo ambiente (Barros \& Arruda, 2010).

Segundo Xavier (2002), os estereótipos são econômicos, pois permitem processar rapidamente a informação social. Desenvolvem-se opiniōes, crenças ou atitudes baseadas em conhecimentos que auxiliem no entendimento do mundo ao redor. O estereótipo caracteriza-se por ser um modelo lógico para resolver um conflito da vida quotidiana e serve sobretudo para dominar o real. Todavia também contribui para o não reconhecimento da peculiaridade de cada indivíduo, a não reciprocidade, o despotismo em determinadas situaçôes (Martins \& Rodrigues, 2003).

O estereótipo, portanto, é uma representação social sobre as características típicas de um grupo, categoria ou classe social (Ayestaran \& Paez, 1987), e toma forma prática por meio de tópicos, ditos, refrões, frases feitas, etiquetas verbais ou adjetivaçôes a respeito de pessoas e grupos, são alusões que frequentemente encontramos, ora nas conversas diárias da rua, ora nos meios de comunicação.

Atitude é um processo relativamente imóvel de organização de experiências e comportamentos interligados com um objeto ou evento particular. Está intrínseco um conceito racional e cognitivo, valores afetivos relacionados a sentimentos e emoções que levam a uma série de orientações comportamentais (Xavier, 2002).

Dessa forma, entende-se o preconceito como uma atitude negativa que um sujeito está propenso a sentir, pensar e conduzir-se em relação a um determinado conjunto. Há também fontes cognitivas de preconceito. $\mathrm{O}$ preconceito pode ser definido como uma atitude hostil ou negativa com relação a um determinado grupo, não levando, necessariamente, a atos hostis ou a comportamentos agressivos (Rodrigues, 1984).

Identificar as representações sociais elaboradas com base em uma prática profissional, como a do psicólogo, é de extrema importância, pois possibilita entender e reconhecer as atitudes positivas ou negativas diante desse profissional. Com a consolidação da entrada do psicólogo no mercado de trabalho no contexto nacional, gerou-se a necessidade de avaliar essa profissão, tanto em termos da organização profissional quanto no tocante à forma como essa prática vinha sendo percebida para que se pudesse conduzir essa profissão na construção de novos saberes (Souza Filho, Oliveira \& Lima, 2006). 


\section{Descrição metodológica}

Esta pesquisa configurou-se como descritiva, de cunho qualitativo e quantitativo, e classificação temporal transversal. Foi realizada nas dependências da UFAM e também na Escola de Enfermagem de Manaus (EEM). Os participantes desta pesquisa são acadêmicos das três grandes áreas do conhecimento humano: Ciências Biológicas (Medicina e Enfermagem), Exatas (Matemática e Engenharia de Produção) e Humanas (Letras, Direito, Administração, Psicologia). Foram pesquisados 60 alunos da área de Ciências Humanas, 30 alunos da área de Ciências Biológicas e 30 alunos da área de Ciências Exatas, sendo o número de alunos equivalente entre os cursos, totalizando 120 acadêmicos.

Foram considerados aptos a participar desta pesquisa, exclusivamente, os alunos que assinaram o termo de consentimento e que estivessem cursando a partir do $5^{\circ}$ semestre, visto que a maioria dos cursos tem, em sua grade curricular, pelo menos uma disciplina equivalente à área da Psicologia até o $5^{\circ}$ semestre. $\mathrm{O}$ instrumento utilizado foi um questionário contendo, na primeira parte, um levantamento sociodemográfico e, na segunda parte, três questões abertas: qual a sua opinião sobre os alunos de Psicologia? Em sua opinião, o que faz o psicólogo? Você já teve algum contato com a Psicologia? Se o teve, comente essa experiência.

Para estudo dos dados, foi empregada a técnica da análise temática ou categorial e, de acordo com Bardin (2002), baseia-se em operações de desmembramento do texto em unidades, ou seja, descobrir os diferentes núcleos de sentido que constituem a comunicação e, posteriormente, realizar o seu reagrupamento em classes ou categorias.

Este estudo foi realizado mediante aprovação no Comitê de Ética e Pesquisa (CEP) da Universidade Federal do Amazonas, protocolado no CEP/UFAM com CAEE no 0234.0.115000-09.

\section{Resultados e discussões}

Depois da coleta de dados, os resultados foram agrupados por categorias, tornando possível descobrir os diferentes núcleos de sentido presentes no discurso dos acadêmicos da Universidade Federal do Amazonas (UFAM), reagrupando-os em classes (Bardin, 2002).

Os resultados das opiniōes sobre os alunos de Psicologia, sendo essa a primeira questão do questionário, apresentaram uma expectativa satisfatória em relação ao objetivo inicial, que foi identificar as representações dos 
alunos. Para a análise de cada curso entrevistado (Medicina, Enfermagem, Letras, Matemática, Direito, Psicologia, Administração e Engenharia de Produção), foram selecionados apenas conteúdos que tiveram uma maior frequência em todas as repostas coletadas.

Os resultados da primeira questão, "Qual a sua opinião sobre os alunos de psicologia?", foram divididos em cinco categorias.

$\mathrm{Na}$ primeira categoria, foram reunidos os termos caracterizados psicometristas e pesquisadores (15\%), por reunirem elementos que são predominantemente característicos de cientistas e investigadores. $\mathrm{Na}$ segunda categoria, o termo principal foi relevância social (25\%), caracterizado por termos relacionados à importância da profissão do psicólogo para a sociedade.

$\mathrm{Na}$ terceira categoria, não diferencia dos outros (10\%), agruparam-se os termos relacionados aos estudantes que não estabeleciam nenhuma diferença em relação a universitários dos outros cursos. Na categoria não sabe (15\%), os universitários entrevistados não conseguiram relacionar nenhuma característica sobre os alunos de Psicologia.

$\mathrm{Na}$ última categoria, outros (35\%), caracterizaram como loucos, doidos, doutores da mente, diferentes, apresentou-se a maior percentagem de estereótipos, pois existem diversos adjetivos para identificar os grupos sociais, sendo os estereótipos uma derivação das representações sociais (Tajfel, 1980).

Nos resultados apresentados acima, sobre a percepção dos acadêmicos em relação aos alunos de Psicologia, percebeu-se que aproximadamente metade dos entrevistados tem noção da contribuição desse aluno para a sociedade. Essa informação é importante, pois, pelo conhecimento da prática profissional do psicólogo, é possível diminuir os estereótipos e os preconceitos. Em contrapartida, parte dos entrevistados tem uma visão estereotipada, citada no item outros, sobre esses alunos. Revelaram um conhecimento insuficiente e desordenado acerca do estudante de Psicologia.

$\mathrm{Na}$ segunda questão, “Em sua opinião, o que faz o psicólogo?”, ocorreu uma maior distribuição percentual das respostas coletadas. Sendo possível determinar cinco características distintas. $\mathrm{Na}$ primeira, foram reunidos os termos ajudar/cuidar (25\%), relacionados ao auxílio dos psicólogos em muitos casos emocionais e na superação de determinados traumas. Na categoria suporte psicológico (20\%), agruparam-se os termos 
relacionados aos benefícios da profissão para o aumento e bem-estar dos indivíduos.

$\mathrm{Na}$ categoria modelo médico/psiquiátrico (15\%), estão relacionados os adjetivos que associaram o trabalho dos psicólogos ao modelo médico tradicional, opiniōes como "trata de loucos" e "trabalha doenças".

$\mathrm{Na}$ quarta categoria, foram agrupadas as características que mais se aproximam do trabalho do psicólogo, denominada promoção de saúde (20\%). Na última categoria, outros (20\%), caracterizaram como " $n \tilde{o} o$ faz nada", estuda a mente, ler a mente das pessoas, relacionaram-se termos diversos e distantes da função do profissional psicólogo.

Quando se trata da prática profissional do psicólogo, os resultados são mais satisfatórios, pois quase $65 \%$ dos acadêmicos têm uma visão mais próxima do que faz o psicólogo. Nota-se um maior nível de informação e maior acurácia na identificação de elementos próprios da atividade. Apesar dos resultados satisfatórios, uma característica muito marcante no discurso dos acadêmicos foi relacionar o psicólogo a um profissional de saúde mental, demonstrando certa identificação deste com a figura do médico.

$\mathrm{Na}$ terceira questão, foi perguntado "Você já teve algum contato com a Psicologia? Se o teve, comente essa experiência". No discurso dos entrevistados, houve um equilíbrio nas respostas. Sobre o contado dos universitários com a Psicologia, as respostas foram de 56\% que sim e 44\% que não.

Em relação às respostas dos acadêmicos que responderam "sim", nos comentários dessa experiência, foram observadas três categorias. A categoria mais abrangente foi a denominada disciplinas, com $70 \%$ das opiniōes dos universitários, sendo esse contato presente em salas de aulas, em disciplinas obrigatórias e em matérias de outros cursos já concluídos.

$\mathrm{Na}$ categoria amigos/parentes (10\%), as experiências foram adquiridas por pessoas próximas, que incentivaram os entrevistados a buscar apoio terapêutico ou introduziram a Psicologia nas suas vidas. A categoria clinical terapeuta (20\%) foi de estudantes cujo primeiro contado foi adquirido diretamente na clínica, com o psicoterapeuta.

Foi possível perceber que ocorrem experiências negativas em relação à matéria Psicologia: 20\% dos entrevistados associaram as aulas de Psicologia a matérias negativas, alegando serem aulas "cansativas" e "chatas", não ocorrendo assim uma completa absorção do conteúdo apresentado. 
Nota-se que a maior parte do contato dos acadêmicos com a Psicologia foi adquirido no contexto acadêmico. Em virtude de tal resultado, torna-se necessário que os profissionais que ministram disciplinas para outros cursos possam ter um mínimo de conhecimento sobre o curso ao qual direcionará suas aulas, pois, no discurso dos alunos, boa parte não consegue associar o conteúdo ministrado de Psicologia ao seu respectivo curso.

$\mathrm{Na}$ última questão, "De que forma a psicologia e, ou, o psicólogo pode contribuir para a sua área de atuação?”, como ocorreram semelhanças entre as repostas de alguns cursos, foi necessário agrupálas para uma melhor análise dos conteúdos. Notou-se que os cursos que apresentaram respostas semelhantes têm características em comum. No primeiro, foram agrupadas Administração e Engenharia de Produção; no segundo, Matemática e Letras; e, no último, Medicina e Enfermagem.

\section{Administração e Engenharia de Produção}

Os primeiros cursos agrupados foram os de Administração e Engenharia de Produção. Vale ressaltar que muitos conteúdos de Administração são ministrados em Engenharia de Produção, mantendo-se, dessa forma, uma relação direta entre os cursos.

As categorias encontradas foram relacionamentos interpessoais (49\%), relacionados ao convívio, aos relacionamentos de trabalho de modo geral. A categoria seleção e treinamento (33\%) apresentaram o maior percentual de respostas, pois, na sua prática profissional, eles têm mais contato com essa definição de psicólogo, sendo que alguns já trabalham em fábricas. Na categoria sem contribuiçôes (18\%), enquadraram-se as respostas dos universitários que não identificaram nenhuma contribuição da Psicologia para a sua área de atuação.

\section{Matemática e Letras}

As respostas das licenciaturas apresentaram características semelhantes. Portanto foram catalogadas as respostas dos dois cursos. Por serem licenciaturas, apresentaram características próprias de profissionais que trabalham em educação e aprendizagem. Apesar de ambas terem conteúdos diferentes e metodologias próprias de ensino em sala de aula.

Os percentuais encontrados foram os de trabalho em equipe (20\%), relacionados ao auxílio do psicólogo na tentativa de propiciar uma melhor 
interação entre os professores, diretores e funcionários da instituição de ensino. O maior percentual foi o na aprendizagem e desenvolvimento do aluno (60\%). Nesta se agruparam-se características que estavam relacionadas aos benefícios que o psicólogo propõe com seus conceitos de desenvolvimento e aprendizagem. Na categoria sem contribuiçôes (20\%), enquadraram-se as respostas dos universitários que não identificaram nenhuma contribuição para a sua área de atuação.

\section{Medicina e Enfermagem}

$\mathrm{Na}$ última análise, agruparam-se as áreas das Ciências Biológicas. Por serem áreas da saúde, estão diretamente relacionadas à Psicologia. $\mathrm{Na}$ primeira categoria, trabalho em equipe (22\%), foram relacionados termos que caracterizam o psicólogo como um agente de integração no ambiente hospitalar, um profissional cujo enfoque será direcionado a melhorar o convívio entre médicos, enfermeiros, técnicos, etc.

$\mathrm{Na}$ categoria no diagnóstico (18\%), foram catalogados termos referentes à interação direta entre médico e psicólogo. Nesse item, os estudantes não excluíram o parecer do psicólogo para possíveis enfermidades caudadas por fatores psicológicos. $\mathrm{Na}$ categoria apoio profissional (30\%), os alunos relacionaram o psicólogo apenas como um complemento no diagnóstico ou tratamento das doenças, podendo ou não influenciar no diagnóstico. $\mathrm{Na}$ última, sem contribuiçôes (30\%), enquadraram-se as respostas dos universitários que não identificaram nenhuma contribuição da Psicologia para a sua área de atuação.

Os resultados encontrados merecem uma profunda reflexão sobre a inserção da Psicologia no sistema hospitalar. Apenas 18\% dos alunos entrevistados sabem da importância do psicólogo nesse contexto, cujo enfoque está direcionado a uma parceria, um trabalho em conjunto, e não apenas como um "coadjuvante" no tratamento dos pacientes.

O dado mais agravante é que quase um terço dos futuros médicos e enfermeiros entrevistados não conseguem relacionar nenhuma contribuição dos psicólogos no âmbito hospitalar.

\section{Considerações finais}

Este estudo buscou verificar a percepção dos alunos da UFAM sobre os alunos de Psicologia e o papel do profissional de Psicologia com base na teoria da representação social. Sendo possível identificar que, apesar 
de existirem diversas visões distorcidas em relação ao papel do psicólogo, existe algum conhecimento em relação à função e à sua contribuição para a sociedade.

Fez parte de nossos objetivos identificar possíveis representaçôes sociais (preconceitos, estereótipos) presentes nos discursos dos acadêmicos. Concluímos que existem, de fato, preconceitos e estereótipos em relação aos alunos de Psicologia, sendo que essa visão negativa, muitas vezes, é em virtude das aulas que são ministradas pelos próprios professores do curso de Psicologia, sendo esta a principal reclamação dos alunos das outras disciplinas.

Detectou-se que muitos alunos não têm o mínimo de conhecimento sobre a Psicologia e o psicólogo. Apesar de estarmos caminhando para uma maior interação entre as diversas áreas do conhecimento, podemos verificar que essa interdisciplinaridade tão sonhada está muito distante em relação às necessidades da nossa sociedade. Percebe-se que boa parte dessas representaçôes é forjada na academia, sendo necessário rever as diretrizes dessa instituição. Nota-se também que ranços estão sendo criados para potencializar estereótipos e preconceitos.

Essa pesquisa buscou um maior número de conhecimentos sobre o tema abordado, sem benefício direto para o participante, mas contribuiu para desmistificar, ampliar o olhar e tentar diminuir os preconceitos e os possíveis estereótipos em relação aos alunos e profissionais de Psicologia.

É necessário que outros estudos direcionados às representaçôes sejam feitos para que possam comprovar ou validar se outros fatores poderiam influenciar os resultados finais desta pesquisa.

\section{Referências}

Almeida, A. M. O. (2009). Abordagem societal das representações sociais. Sociedade e Estado, 24, 713-737.

Ayestaran, S. \& Paez, D. (1987). Representaciones sociales y estereotipos grupales. In P. R. Darío et al. (Org.). Pensamiento, individuo y sociedad: cognición y representación social (pp. 221-262). Madrid: Fundamentos.

Bardin, L. (2002). Análise de conteúdo. (L. A. Reto \& A. Pinheiro, Trad.). Lisboa: Ediçōes 70. 
Barros, C. F. Pombo de \& Arruda, A. M. S. (2010). Afetos e representações sociais. Psicologia: Teoria e Pesquisa, 26, 351-360.

Guareschi, P. A. \& Jovchelovitch, S. (Orgs.). (1994). Textos em representaçôes sociais. Petrópolis: Vozes.

Martins, R. \& Rodrigues, M. (2003). Estereótipos sobre idosos: uma representação social gerontofóbica. Educação, Ciência e Tecnologia, 29, 249-254.

Moscovici, S. (2003). Representaçôes sociais: investigaçôes em Psicologia Social. (P. A. Guareschi, Trad.). Petrópolis: Vozes. [Trabalho original publicado em 2000].

Oliveira, M. S. B. de (2004). Representações sociais e sociedades: a contribuição de Serge Moscovici. Revista Brasileira de Ciências Sociais, 19,180-186.

Porto, M. S. G. (2009). Representaçôes sociais: entre a Sociologia e a Psicologia Social - um espaço para o debate interdisciplinar. Sociedade e Estado, 24, 645-652.

Rodrigues, A. P. (1984). Atitude e crença em relação a preconceito racial e ao estereotipo sexual no Brasil. Relatório técnico, 2. Rio de Janeiro: FGV; ISOP; CBPP.

Souza Filho, M. L., Oliveira, J. S. C. \& Lima, F. L. A. (2006). Como as pessoas percebem o psicólogo: um estudo exploratório. Paidéia (Ribeirão Preto), 16, 253-261.

Tajfel, H. (1980). Comportamento intergrupo e Psicologia social da mudança: mudança social e Psicologia social. Lisboa: Livros Horizonte. [comunicaçóes apresentadas ao Simposium sobre Mudança em Psicologia Social]

Xavier, R. (2002). Representação social e ideologia: conceitos intercambiáveis?. Psicologia e Sociedade, 14, 18-47. 